\title{
Synotis panzhouensis (Asteraceae, Senecioneae), a distinct new species with red-purple pappus from southwestern Guizhou, China
}

\author{
Zhi Li', Hai-Lei Zheng'2, Ming Tang ${ }^{3}$ \\ I College of Forestry, Guizhou University, Guiyang, 550025, Guizhou, China 2 Wild Dali Nature Educa- \\ tion and Research Center, Dali 671000, Yunnan, China 3 College of Forestry, Jiangxi Agricultural University, \\ Nanchang 330045, Jiangxi, China
}

Corresponding author: Ming Tang (tangming@jxau.edu.cn)

Academic editor:A. Sukhorukov | Received 14September 2020 | Accepted 12 October 2020 | Published 29 October 2020

Citation: Li Z, Zheng H-L, Tang M (2020) Synotis panzhouensis (Asteraceae, Senecioneae), a distinct new species with red-purple pappus from southwestern Guizhou, China. PhytoKeys 166: 79-86. https://doi.org/10.3897/ phytokeys. 166.58654

\begin{abstract}
A new species of Asteraceae, Synotis panzhouensis, is described and illustrated from Guizhou Province in China. Compared with other species of the genus, it is distinguishable by having red-purple pappus; additionally, it differs from its closest ally $S$. nayongensis by the larger involucres and phyllaries, and higher number of phyllaries and disk florets. In addition, detailed discussion of morphological differences, the provisional IUCN status and a distribution map are provided.
\end{abstract}

\section{Keywords}

Asteraceae, new species, Senecioneae, taxonomy, Synotis nayongensis

\section{Introduction}

Synotis (Clarke) C.Jeffrey \& Y.L.Chen (Asteraceae, Senecioneae) includes 60 annual and sub-shrubby species predominantly distributed in northern India, Nepal, Bhutan, northern Myanmar, Thailand, Vietnam and southern China (Jeffrey and Chen 1984; Chen 1999; Chen et al. 2011; Tang 2014; Joshi et al. 2013). The genus was separated from Senecio L. mainly due to the anther bases having sterile tailed auricles 
(vs. without sterile tailed auricles) (Jeffrey and Chen 1984). For China, many taxonomic and nomenclatural novelties within the genus have been reported in recent years (Tang et al. 2013a, b, c, 2014, 2017; Tong et al. 2017; Li et al. 2018), and at the present time, approximately 50 species are recorded in China, of which 24 are endemic (Tang 2014, Tang unpublished data).

During an expedition to Panzhou, Guizhou Province, China in 2020, we found an unusual population of Synotis at pre-anthesis. Initially, the plants seemed to be similar to $S$. nayongensis C.Jeffrey \& Y.L.Chen, but further examination revealed several diagnostic differences between the Guizhou population and S. nayongensis; therefore, we describe the Guizhou plants as a new species to science here.

\section{Material and methods}

Herbarium studies were conducted in GZAC, IBSC, JXAU, KUN, and PE. Field observations were made in Panzhou, Guizhou, China in August and September 2020.

\section{Results and discussion}

Synotis panzhouensis M.Tang \& H.L.Zheng, sp. nov.

urn:lsid:ipni.org:names:77212605-1

Figs 1, 2

Type. China. Guizhou Province, Panzhou, Dazhai village, west of Luotuo valley, limestone mountains, $1803 \mathrm{~m}$ a.s.l., herbaceous tier in mixed forest, $26^{\circ} 04^{\prime} 37.59^{\prime \prime} \mathrm{N}$, 10451'47.40"E, 1 September 2020, Z. Li \& M. Tang 2020-0901 (holotype JXAU! isotypes GZAC! JXAU!).

Diagnosis. Synotis panzhouensis is similar to $S$. nayongensis but differs from the latter species by its larger involucral bracts $(7-8 \times 3-4 \mathrm{~mm}$ vs. $5-6 \times 2-2.5 \mathrm{~mm})$ and phyllaries $(7-8 \times 2-3 \mathrm{~mm}$ vs. $5-6 \times 1-1.5 \mathrm{~mm})$, higher number of phyllaries $((7) 8$ vs. 5 ) and disk florets ( $8-11$ vs. $4-5$ ), different colour of phyllaries (green vs. white with green apex) and pappus (red-purple vs. white).

Description. Perennial herbs, erect, rhizomatous. Rhizome thick, horizontal. Vegetative stem solitary, erect, $20-35 \mathrm{~cm}$, densely white or ferruginous setulose. Flowering stem solitary, erect, scapiform, 30-60 cm tall, shortly branching, fulvous tomentose. Leaves rosulate at the base of fertile shoot; petioles $1-1.5 \mathrm{~cm}$ long, not winged, slightly expanded at base; blades oblanceolate or obovate, $10-18 \times 2.5-5 \mathrm{~cm}$, papyraceous, abaxially sparsely arachnoid, glabrescent or subglabrous, adaxially scattered setulose, pinnately veined, lateral veins $12-16$, arcuate-ascending, base cuneate, margin shallowly sinuate-apiculate or repand-apiculate, apex subacute-acuminate. Stem leaves on reproductive shoots few, narrowly lanceolate, remote, much smaller. Capitula discoid, numerous, arranged in an attenuate narrowly paniculoid thyrse; pedicels $3-5 \mathrm{~mm}$, fulvous tomentose, 1- or 2- bracteate; bracts below capitula linear, 5-10 mm long. 


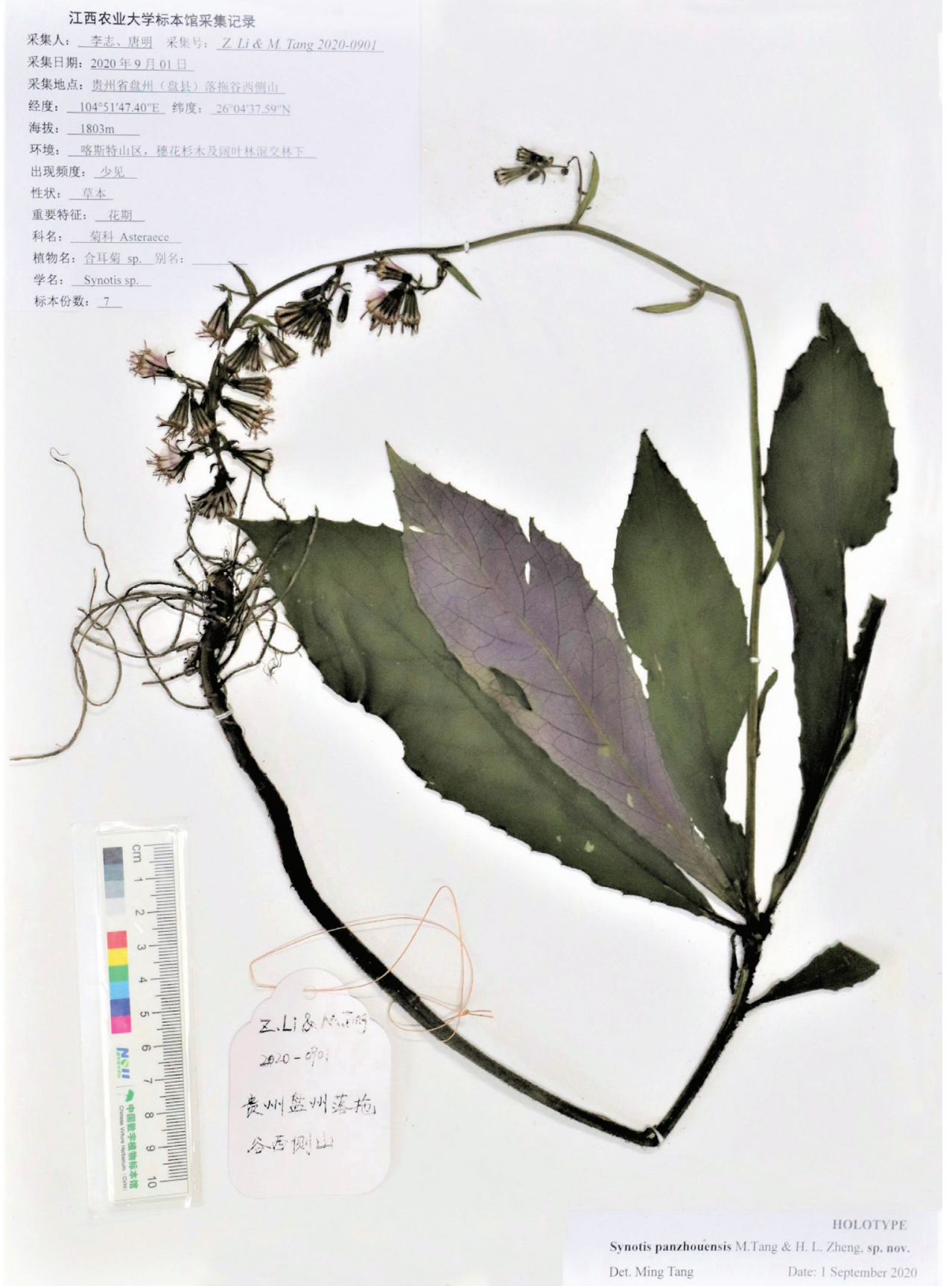

Figure I. Holotype of Synotis panzhouensis (Panzhou, Guizhou, China, Z. Li \& M. Tang 2020-0901 (JXAU)).

Involucres narrowly campanulate, 7-8 × 3-4 mm, calyculate; bracts of calyculus 3-5, ovate-oblong or lanceolate, $1 / 4-1 / 3$ as long as phyllaries; phyllaries (7) 8 , narrowly oblong, 2-3 mm wide, herbaceous, green, margin narrowly scarious, glabrous, not 

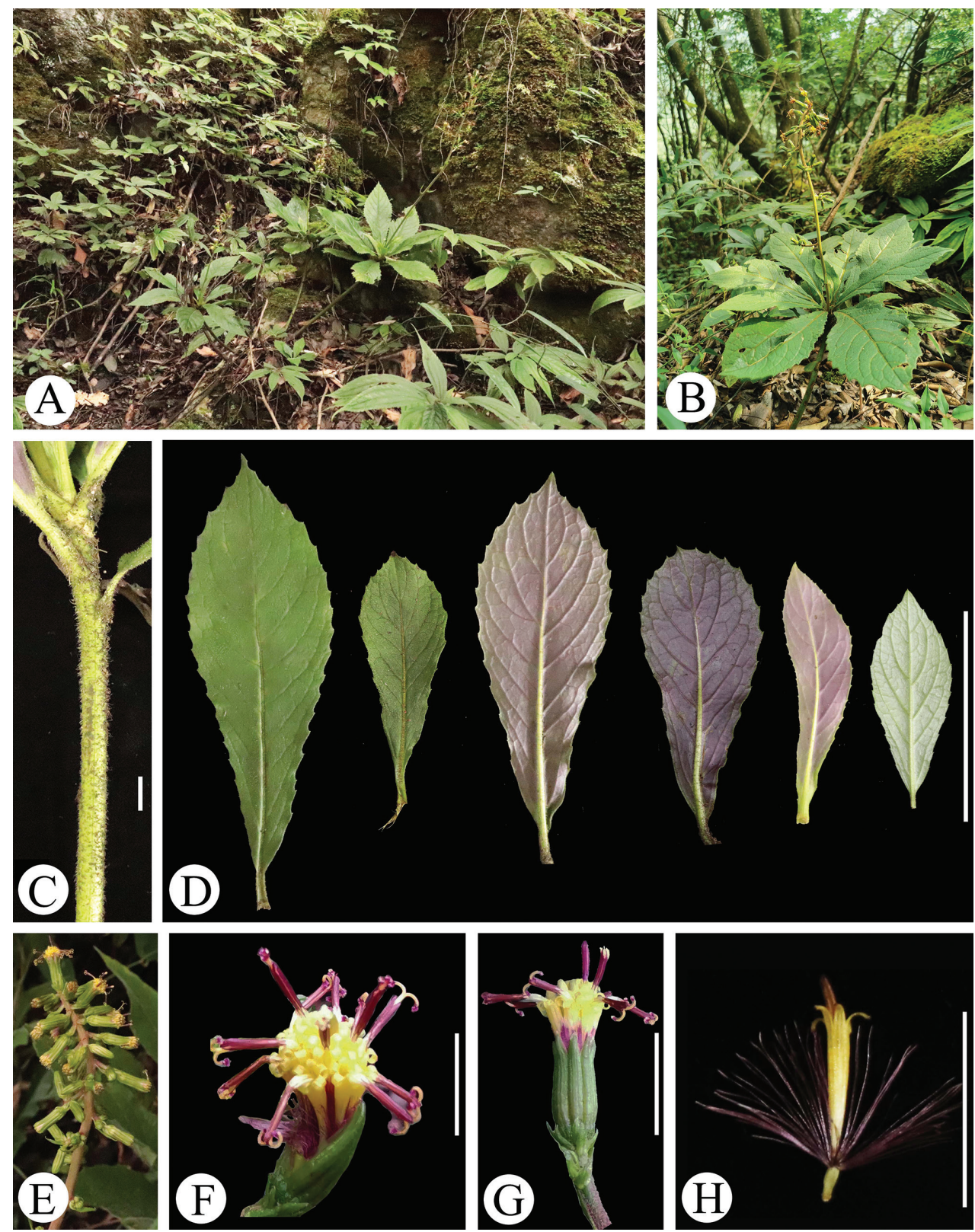

Figure 2. Synotis panzhouensis in the wild (Dazhai village, Panzhou, Guizhou, China). A habitat $\mathbf{B}$ general habit $\mathbf{C}$ portion of vegetative stem $\mathbf{D}$ leaf blades (left two: adaxial surface; right four: abaxial surface) $\mathbf{E}$ synflorescence $\mathbf{F}$ capitulum (top view) $\mathbf{G}$ capitulum (side view) $\mathbf{H}$ a disk floret with red-purple pappus. Scale bars: $5 \mathrm{~mm}(\mathbf{C}) ; 10 \mathrm{~cm}(\mathbf{D}) ; 4 \mathrm{~mm}(\mathbf{F}) ; 1 \mathrm{~cm}(\mathbf{G}, \mathbf{H})$.

veined, apically triangular, obtuse. Ray florets absent. Disk florets 8-11; corolla yellow, 8-10 mm, with tube 7-8 $\mathrm{mm}$ long, limb narrowly funnelform, somewhat exserted from involucre; lobes oblong-lanceolate, 1-2 mm long, apically acute. Anthers $3.5-4 \mathrm{~mm}$ long, anther tails equaling anther-collars; appendages lanceolate; anther- 

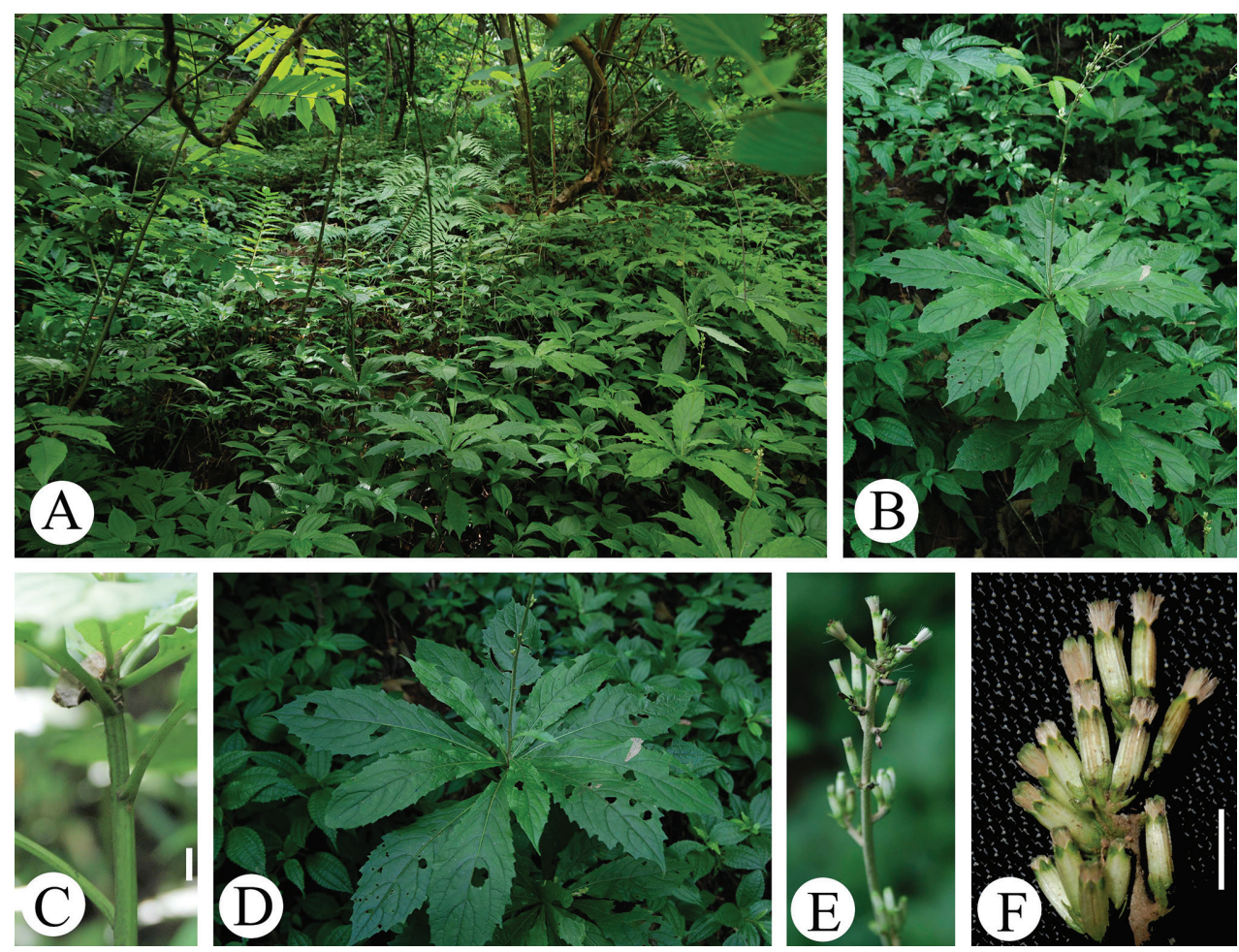

Figure 3. Synotis nayongensis in the wild (Luzui village, Nayong, Guizhou,China). A habitat B habit $\mathbf{C}$ portion of vegetative stem $\mathbf{D}$ leaf blades from the adaxil view $\mathbf{E}$ synflorescence $\mathbf{F}$ portion of synflorescence (side view, note the white phyllaries with green apex, and also note the white pappus). Scale bars: $5 \mathrm{~mm}(\mathbf{C}) ; 6 \mathrm{~mm}(\mathbf{F})$.

collars balusterform, basally dilated. Style branches $1.8-2 \mathrm{~mm}$ long, covered with long marginal papillae and often with a central tuft not conspicuously longer. Achenes ca. $2 \mathrm{~mm}$, glabrous. Pappus 8-10 mm long, red-purple.

Distribution. Synotis panzhouensis is endemic to southwestern Guizhou, China (Fig. 4); to date, only known from the type population.

Habitat. Growing in mixed forest with other herbs in limestone mountains at an elevation of $-1800 \mathrm{~m}$.

Phenology. Flowering from late August to September; fruiting October.

Etymology. The specific epithet is derived from Panzhou, the type locality of the species. The Chinese name is '盘州合耳菊 (Pan zhou he er ju)'.

Discussion. As shown in Figs 1-3, Synotis panzhouensis is similar to S. nayongensis in the oblanceolate or obovate rosulate leaves at the base of synflorescence, the narrow paniculoid thyrse and absence of ray florets. However, we detected significant differences between the two species as listed in Table 1 .

Synotis panzhouensis is only distributed in Panzhou, southwestern Guizhou, China, while $S$. nayongensis is mainly distributed around northwestern Guizhou (Ruan et al. 2020), with its type locality in Nayong, a county located $200 \mathrm{~km} \mathrm{NE}$ from Panzhou. 
Table I. Comparison of Synotis panzhouensis and S. nayongensis.

\begin{tabular}{l|c|c}
\hline \multicolumn{1}{c|}{ Characters } & Synotis panzhouensis & S. nayongensis \\
\hline $\begin{array}{l}\text { Indumentum of } \\
\text { vegetative stem }\end{array}$ & densely white to ferruginous setulose & sparsely pubescent, glabrescent to glabrous \\
\hline Petioles & $1-1.5 \mathrm{~cm}$ & petiole $1-2.5 \mathrm{~cm}$ \\
\hline Leaf blades & adaxially green or purple & adaxially green \\
\hline Flowering stem & fulvous tomentose, not glabrescent & thinly tomentose, glabrescent \\
\hline Involucres & $7-8 \times 3-4 \mathrm{~mm}$ & $5-6 \times 2-2.5 \mathrm{~mm}$ \\
\hline Phyllaries & $(7) 8,7-8 \times 2-3 \mathrm{~mm}$, green, not veined & $5,5-6 \times 1-1.5 \mathrm{~mm}$, white, apex green, conspicuously 3-5-veined \\
\hline Disk florets & $8-11$, deep yellow, lamina yellow & $4-5$, yellowish, lamina yellow-whitish, apex green when young \\
\hline Anthers & red-purple & yellow-whitish \\
\hline Achenes & ca. $2 \mathrm{~mm}$ long & ca. 4 mm long \\
\hline Pappus & red-purple & white \\
\hline
\end{tabular}

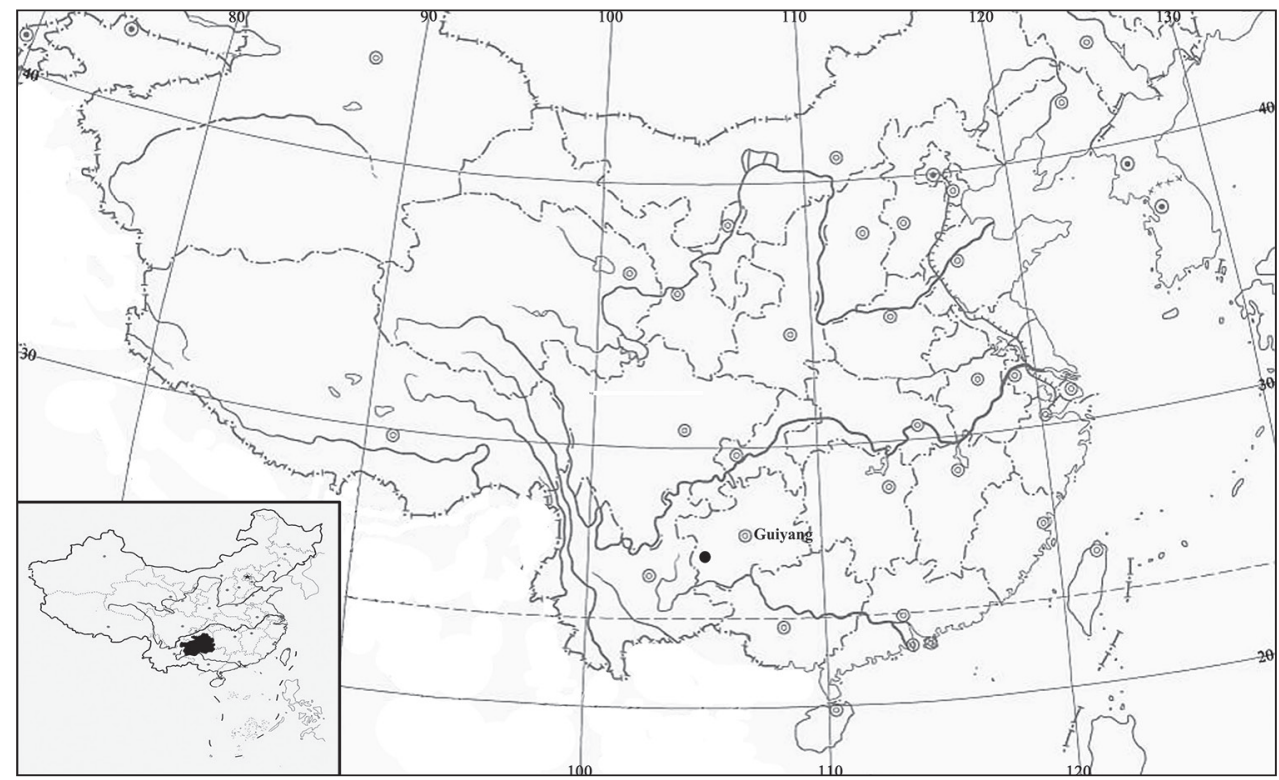

Figure 4. Record of Synotis panzhouensis.

From all other species of Synotis, S. panzhouensis is very distinct in the red-purple pappus. According to our observation of the plants in vivo, as well as a critical examination of taxa throughout the genus, most species ( -50 spp.) have white pappus. Five species in sect. S. ser. Fulvipapposae C.Jeffrey \& Y.L.Chen often have white or stramineous pappus, which is consistent with the descriptions reported by Jeffrey and Chen (1984), Chen (1999) and Chen et al. (2011). The pappus colour of S. vaniotii (Lévl.) C.Jeffrey \& Y.L.Chen and S. palmatisecta Y.L.Chen \& D.J.Liu were described as rubescent, but this might be the result of inattentive observation, for both of the species were found with white, or rarely pale brown pappus during our field and herbarium observations. It is noteworthy to mention that $S$. chenopodiifolia (DC.) M.Tang, C.Ren \& Q.E.Yang, a species always reported with brown or yellow pappus, has been reported with a dark purple pappus in a population in Gyirong County (Tang et al. 
2014), but such variation is rather atypical in the species. Synotis chenopodiifolia is a plant to $80-180 \mathrm{~cm}$ with triangular-ovate or triangular-hastate leaves and a capitulum with 5 phyllaries, 2 or 3(-4) disk florets, and it obviously differs from the leaf characters and capitulum characters as seen in S. panzhouensis.

Morphologically, following the characters and delimitation of Jeffrey and Chen (1984) and Tang (2014), S. panzhouensis is best referred to Synotis sect. Synotis ser. Synotis due to the leaves gathered at the apex of the vegetative stem and its terminal inflorescence.

IUCN Red List Category. Synotis panzhouensis was found in a single location with an extremely small population in Panzhou, southwestern Guizhou, China. Due to the remote distance and difficult and dangerous accessibility to the type locality, the population was not disturbed by human activity and currently appears to be growing very well. However, according to our observation, the population comprises no more than 100 plants, and with a small geographical range of no more than $1000 \mathrm{~m}^{2}$, we recommend that $S$. panzhouensis be categorized as Critically Endangered (CR) using criteria $\mathrm{B}$ and C following the IUCN Red List categories (IUCN 2019).

\section{Acknowledgements}

We are grateful to Dr. Alexander P. Sukhorukov, Dr. Timothy M. A. Utteridge and two anonymous reviewers for their helpful comments on how to improve our manuscript. We thank Dr. P. Li from Zhejiang University for his help in the field work, and the staff of IBSC, GZAC, JXAU, KUN and PE for allowing us to examine and use their scanned images of specimens. This work was supported by the National Science Foundation of China (grant No. 31960043), the Science and Technology Basic Resources Investigation Program of China "Survey and Germplasm Conservation of Plant Species with Extremely Small Populations in South-west China” (grant No. 2017FY100100), and also in part by the Research Projects of Introducing Talents in Guizhou University (grant No. Gui Da Ren Ji He Zi (2019)59).

\section{References}

Chen YL (1999) Senecioneae Cass. In: Chen YL (Ed.) Flora Reipublicae Popularis Sinicae, vol. 77. Science Press, Beijing, 1-326. [In Chinese]

Chen YL, Nordenstam B, Jeffrey C (2011) Synotis (C.B.Clarke) C.Jeffrey \& Y.L.Chen. In: Wu ZY, Raven PH (Eds) Flora of China, vol. 20-21. Science Press, Beijing \& Missouri Botanical Garden Press, St. Louis, 489-505.

Jeffrey C, Chen YL (1984) Taxonomic studies on the tribe Senecioneae (Compositae) of Eastern Asia. Kew Bulletin 39(2): 205-446. https://doi.org/10.2307/4110124

Joshi S, Shrestha K, Bajracharya DM (2013) Synotis managensis (Senecioneae: Asteraceae) - a new species from Manang. Central Nepal. Pleione 11(2): 177-186. https://doi. org/10.26679/Pleione.11.2.2017.177-186 
Li HM, Lazkov GA, Illarionova ID, Tong TJ, Shao YY, Ren C (2018) Transfer of Senecio karelinioides (Asteraceae-Senecioneae) to Synotis based on evidence from morphology, karyology and ITS/ETS sequence data. Nordic Journal of Botany 32: 1-12. https://doi. org/10.1111/njb.01838

Ruan YQ, Liu YL, Wu XH, Yu F, Tang M (2020) A newly recorded species and clarification of the distribution record of another species within Synotis in Yunnan. Journal of Gansu Agricultural University 55(2): 112-123. [In Chinese]

IUCN (2019) Guidelines for Using the IUCN Red List Categories and Criteria version 14 [EB/OL]. 2020-04-10. Prepared by the Standards and Petitions Subcommittee. https:// www.iucnredlist.org/documents/RedListGuidelines.pdf

Tang M (2014) A Systematic Study of the Genus Synotis (Compositae-Senecioneae). PhD thesis. University of Chinese Academy of Sciences, Beijing. [In Chinese]

Tang M, Wang LY, Yang QE (2013a) Synotisxinningensis (Asteraceae), a new species from Hunan, China. Botanical Studies (Taipei, Taiwan) 54(1): e16. https://doi.org/10.1186/19993110-54-16

Tang M, Hong Y, Yang QE (2013b) Synotis baoshanensis (Asteraceae), a new species from Yunnan, China. Botanical Studies (Taipei, Taiwan) 54(1): e17. https://doi.org/10.1186/19993110-54-17

Tang M, Wang LY, Yang QE (2013c) The identity of Synotis cordifolia (Asteraceae-Senecioneae). Journal of Tropical and Subtropical Botany 21: 101-108. [In Chinese]

Tang M, Ren C, Yang QE (2014) Parasenecio chenopodiifolius (Compositae-Senecioneae) is a Synotis and conspecific with $S$. otophylla based on evidence from morphology, cytology and ITS/ETS sequence data. Nordic Journal of Botany 32(6): 824-835. https://doi.org/10.1111/njb.00574

Tang M, Ren C, Yang QE (2017) Reinstatement of the Sino-Himalayan species Seneciopentanthus (Asteraceae, Senecioneae). Phytotaxa 292(3): 253-261. https://doi.org/10.11646/phytotaxa.292.3.5

Tong TJ, Tang M, Ren C, Yang QE (2017) Senecio kumaonensis (Asteraceae, Senecioneae) is a Synotis based on evidence from karyology and nuclear ITS/ETS sequence data. Phytotaxa 292(1): 35-46. https://doi.org/10.11646/phytotaxa.292.1.3 